\title{
Acerca del uso del tiempo apocalíptico en la Edad Media
}

\author{
José Luis Villacañas Berlanga
}

Universidad de Murcia

\begin{abstract}
REsumen. Tras un primer apartado dedicado a sintetizar las tesis básicas del escrito de Reinhart Koselleck Zeitverkürzung und Beschleunigung, el texto discute algunas de sus conclusiones nucleares, como la identificación de mundanización, temporalización y aceleración. En el análisis es fundamental la reflexión acerca del uso del tiempo apocalíptico en la Edad Media. Así, se critica como simplificadora la presentación del Apocalipsis cristiano como aceleración profana, última consecuencia de la secularización. El ensayo se cierra con la disolución de la secuencia temporal entre acortamiento y aceleración, acción humana y acción divina, tiempo del ser humano y tiempo de la trascendencia, que han convivido en verdad dialécticamente.
\end{abstract}

Palabras clave: Koselleck, temporalización, aceleración, secularización, apocalipsis cristiano.
Abstract. After a first section in which the essential thesis of Reinhart Koselleck's work Zeitverkürzung und Beschleunigung are synthesized, the text discusses some of its main conclusions. In the analysis is very important the reflection about the use of apocalyptic time in the Middle Ages. So, the paper criticizes the way the Christian Apocalypse is presented as profane acceleration, last consequence of secularization. The essay ends by breaking up the temporal sequence between reduction and acceleration, human action and divine action, the time of humans and the time of transcendence, which have indeed coexisted in a dialectical way.

Key words: Koselleck, temporalization, acceleration, secularization, Christian Apocalypse.

\section{Secularización y su experiencia temporal}

No se me reprochará que entienda esta colaboración como un homenaje a R. Koselleck, cuyo trabajo ha iluminado mi tarea en la última década. Sin embargo, mi ensayo ofrece un homenaje doble, ya que voy a concentrarme en una temática que ha sido tratada por nuestro autor de forma específica en su escrito Zeitverkürzung und Beschleunigung. Como este trabajo ha sido traducido por Faustino Oncina, también deseo de este modo reconocer el trabajo de alguien con quien tuve el placer de compartir la introducción de la edición española de Historia y Hermenéutica (Barcelona, Paidós, 1997). 
Ante todo, el mejor homenaje, el ejercido por el imperativo de la comprensión. A recibir el elegante escrito sobre el acortamiento del tiempo dedicaré mi primer punto. Como es sabido, el texto de Koselleck tiene un subtítulo que determina su planteamiento. Él trata de estudiar el acortamiento y la aceleración del tiempo en el seno de una teoría sobre la secularización. Partiendo de las visiones de la Sibila Tiburtina y de su máxima «Y los años se acortarán a meses y los meses a semanas y las semanas a días y los días a horas», Koselleck desea mostrar las transferencias de sentido desde un mundo sagrado hasta un escenario temporal inmanente. Al hacerlo no ha tenido en cuenta las críticas de Blumenberg al concepto de secularización, desde luego. En la defensa de una teoría de la secularización, Koselleck se mantiene en el universo teórico de Carl Schmitt, quien siempre creyó en la imposibilidad de una desnuda inmanencia con sentido autónomo ${ }^{1}$. La autoafirmación de la finitud sin modelo teológico le parecía inviable como forma productora de sentido $^{2}$. Esta actitud moderna era leída por Schmitt como una creatio ex nihilo y al rechazarla, tanto él como Koselleck no hacían sino mantenerse fieles al mundo clásico, que necesitaba un modelo arquetípico teológico, un comparativo ontológico. La teoría de la secularización sería, en este sentido, la última metamorfosis del platonismo ${ }^{3}$. Al olvidar su procedencia de los órdenes cristianos, la modernidad abriría un basto proceso de usurpaciones ilegítimas. La teoría de la secularización se convierte así en una teoría sobre la ilegitimidad de la modernidad.

Como es sabido, el acortamiento del tiempo forma parte de la estructura de la segunda venida de Cristo, y marca el final del eón cristiano y de las seis edades del mundo, antes de dar paso a la nueva tierra y al nuevo cielo, en esa novitas nova que Benjamin subrayara con tanta admiración como el propio Schmitt. El uso de esta noción de acortamiento para entender la aceleración del tiempo inmanente, ya al margen de la Segunda venida de Cristo, constituye para Koselleck un caso de secularización.

No debemos negar que hay un vínculo intuitivo entre estas experiencias. Por su estructura misma, tenemos secularización cuando un elemento que tie-

1 Para la relación entre Blumenberg y Schmitt, cf. Die Legitimität der Neuzeit y luego la respuesta de Schmitt en Politische Theologie II. Para esto se puede ver mi trabajo «Ontología y conflicto: ¿Qué podemos aprender de Schmitt al leerlo desde Freud?».

${ }^{2}$ H. Blumenberg, Die Legitimität der Neuzeit, Frankfurt, Suhrkamp, 1988.

3 Desde este punto de vista, la teoría de la secularización ha sido llamada «una interpretación sustancialista de la historia, aunque sea de forma debilitada, en la cual se realiza el absoluto» (Gianni Carchia, «Platonismus der Inmanenz. Phänomenologie und Geschichte», en Franz J. Wetz y Hermann. Timm, Die Kunst des Überlebens. Nachdenken über Hans Blumenberg, Frankfurt, Suhrkamp, 1999, p. 333). Para el tema del sustancialismo histórico, cf. Jean Cl. Monod, «Métaphores et métamorphoses. Blumenberg et le substantialisme historique», Revue germanique international, 10, 1998, pp. 215-230. Del mismo autor se debe ver La querelle de la sécularisation de Hegel a Blumenberg, París, Vrin, 2002, que es un buen resumen de la problemática. 
ne un sentido sagrado se moviliza, se transfiere y surte efectos en ámbitos de sentido de la inmanencia. Tal cosa, aplicada a los bienes materiales de la Iglesia, ocurrió en la paz de Westfalia y luego en la Francia revolucionaria. De ahí el contexto jurídico canónico básico de la teoría, uno que Koselleck conoce y recuerda ${ }^{4}$. Pero lo mismo se podría aplicar a los bienes conceptuales, con los que las instituciones fundan sus pretensiones de legitimidad. De hecho, esta transferencia institucional es la que señaló Weber y la única que él entendía por secularización ${ }^{5}$. Estos bienes conceptuales e institucionales definirían primero las relaciones con la trascendencia y la gracia y servirían luego para ordenar las instancias del mundo. En este mismo sentido - aunque en dirección contraria - pudo hablar Carl Schmitt de la política como una construcción derivada de la metafísica y de la teología en el siglo XVII. En este tiempo, y con la formación del soberano del Estado desde la categoría de potestas absoluta, se habría dado una primera secularización conceptual de la subjetividad voluntarista del Dios moderno.

Vemos así que el gran camino de la teoría clásica de la secularización se concentraba sobre todo en las prácticas institucionales. Ahora la recordaré brevemente. Desde este punto de vista, más que una usurpación, el proceso describe el mandato de las instancias de la trascendencia que impone transformar o glorificar los órdenes de la inmanencia, asegurando de manera práctica, y mediante la misión ético-religiosa, una mimesis que ya no estaba garantizada por la ontología platónica. Se ha señalado que ya la misma institución de la Iglesia militante, la iglesia institucional en la tierra, es en este sentido una secularización de la trascendencia de la ciudad de Dios, o iglesia triunfante. Difícilmente se puede hablar aquí de transferencia ni de usurpación, sino de expansión, pues tenemos el mismo programa de salvación del mundo. Koselleck recuerda la tesis de Overbeck de que la teología mundanizó el cristianismo originario ${ }^{6}$. Podríamos decir con Nietzsche y Schmitt que

${ }^{4}$ R. Koselleck, Aceleración, prognosis y secularización, Valencia, Pre-Textos, 2003, p. 43.

5 La palabra «Säkularisationprozess» aparece en el contexto del artículo de 1906 sobre las sectas protestantes, muy en la línea de G. Jellinek. Para esto se puede ver mi Introducción a Ética protestante y el espíritu del capitalismo, Madrid, Akal, 2. ${ }^{a}$ ed., 1998, pp. 54-61. Weber habla de las sectas como un «instituto de gracia» y muestra cómo los procedimientos sectarios prefiguran los procedimientos de los clubs democráticos. «Lo decisivo era la aceptación mediante una votación realizada tras un examen y tras la confirmación ética en el sentido de aquellas virtudes que premiaba el ascetismo intramundano del protestantismo, es decir, la vieja tradición puritana. Visto de más cerca, se trataba del progreso continuo de aquel característico proceso de «secularización» del que en tiempos modernos han sido víctimas esos fenómenos surgidos de concepciones religiosas». Edición citada, pp. 269-270. Se trataba así de procesos formales de transferencia de procedimientos de asociación y de reclutamiento de los individuos. Parsons, siguiendo la línea de Weber, pudo hablar de secularización como institucionalización del espíritu de las sectas protestantes, en un sentido que repetía el gran camino de la catolicidad latina. Cf. Talcott Parsons, «Belief, Unbelief und Disbelief», en Action theory and the human condition, New York, The Free Press, 1978, p. 241.

${ }^{6}$ Koselleck, op. cit., p. 45. 
lo politizó. Es más, desde el momento mismo de la fundación cristiana, basada en una dualidad radical entre Dios y el Mundo propia de una pequeña secta profética y acósmica, se habría abierto camino un creciente pacto con el mundo. El desprecio cristiano por el tiempo, su radical anclaje en el presente, habría dado paso a cierta expectativa de futuro. Como podemos suponer, este paso significó otras tantas negociaciones y aplazamientos del problema de la Segunda venida. No hay que recordar que las consideraciones contra el tiempo presente de Nietzsche, un buen amigo de Overbeck, surgen de aquí ${ }^{7}$. Sin embargo, la expansión cristianizadora y la introducción del vector del futuro, no disolvieron el germen negador del mundo y la aspiración acósmica. En ese momento del paso de la iglesia militante a la triunfante, se alojó el germen acósmico cristiano y desde él regresó con fuerza y se impuso sobre las mediaciones institucionales. Como recordó hace mucho Weber, la historia del cristianismo, mejor que desde una historia de la secularización, se podría realizar desde la dialéctica perenne de carisma y derecho, acosmismo e institución. Nosotros podríamos glosar estas formas de la complexio oppositorum con otra dualidad: Apocalipsis y poder.

Lejos de estas inspiraciones weberianas, Koselleck evade esa historia de largo alcance por una tesis que pretende abarcar sólo la modernidad. Además, en lugar de concentrarse en las instituciones, él pasará a analizar experiencias más básicas. Entonces prefiere hablar de temporalización como la estructura misma de la secularización. Hablando de esta temporalización de la historia, Koselleck dice que es la noción moderna de un tiempo que pretende organizarse a sí mismo: «ordenar el tiempo histórico según criterios que se puedan derivar desde el conocimiento de la historia misma». En este contexto cita a Kant y dice que en lugar de que la historia siga a la cronología (como lo había hecho con el viejo esquema de las Seis edades del mundo), ahora la cronología debe seguir a la historia. La medida del tiempo ya no se da por supuesta, sino que se construye ${ }^{8}$. Aquí es donde la tesis específica de la secularización se hace fuerte en Koselleck. Pues esta temporalización no es ajena a un ideal derivado del cristianismo. Tal cosa sucede no tanto cuando la institución ce-

7 No se trata sólo del texto Über die Christlichkeit unserer heutigen Theologie, Streit und Friedensschrift, Leipzig, 1973, sino también de Christentum und Kultur. Gedanken und Anmerkungen zur modernen Theologie, Schwabe, Basilea, 1919. Allí se contrapone el cristianismo originario contra el cristianismo instalado y acomodado a los poderes. La tesis del rechazo del mundo del cristianismo primitivo inspiró la tesis del rechazo del siglo de Nietzsche, que era electivamente afín con la filosofía educadora de Schopenhauer. De hecho todas las tesis de las Consideraciones intempestivas tienen este regusto. Enemistad con el mundo e inactualidad eran casi sinónimos para Nietzsche, que de esta manera quería detener la inspiración secularizada del falso cristianismo burgués. El filósofo sería así el antagonista de la secularización, una especie de catechontos invertido. Cf. Nachgelassene Fragmente, 1869-1874, 35, 12, de Primavera y verano de 1874, KSA, 7, p. 814. Para desarrollos ulteriores, cf. Monod, op. cit., p. 86 ss.

8 Cf. «Moderne Sozialgeschichte und historische Zeit», en R. Koselleck, Zeitschichten, Frankfurt, Suhrkamp, 2000, p. 322. 
leste de la Ciudad de Dios se proyecta como iglesia en la tierra, en un juego de mimesis que todavía resulta fascinante perseguir, sino cuando las promesas de la Ciudad de Dios se han de realizar en el tiempo mismo, y no en el más allá. Se trata de la divisa idealista del reino de Dios en la Tierra, y de la transformación kantiana de la inmortalidad del alma en el carácter indefinido del tiempo de la especie humana. Entonces la historia no es lo que termina para que se abra el reino de Dios, sino el tiempo en el que tal reino se realiza y como tal se experimenta ${ }^{9}$. Se trata de lo que en otro escrito Koselleck ha llamado la «temporalización de la Utopía» ${ }^{10}$. Aquí ya no depende de Carl Schmitt sino de Karl Löwith, otro de sus maestros.

Esta idea — la historia sigue teniendo una meta ${ }^{11}$ — tiene que ver en su opinión, y en la de Löwith, con la secularización de las esperanzas cristianas como presupuesto de la mundanización ${ }^{12}$. No debemos tener duda de que Koselleck acepta esta visión de las cosas. En un pasaje expone esta misma idea con la palabra adecuada: «Desde entonces la salvación [...] es buscada en el desarrollo y ejecución de la historia misma» ${ }^{13}$. Se trata por tanto de la esperanza cristiana de salvación. Su transferencia intrahistórica altera su contenido y la forma del tiempo. Ahora la nueva Jerusalén, como objetivo histórico inmanente, consiste en democratizar la tierra entera ${ }^{14}$. A esta democratización se asocia de forma rígida la felicidad universal y ésta viene asegurada por el éxito técnico. El problema de la secularización se complica por la transferencia de sentido de la meta - la salvación-, al mundo, pero también por el cambio de sujeto: «Ya no es Dios el señor de la acción, sino que lo es el hombre que provoca el progreso» ${ }^{15}$. Y en la medida en que el propio ser humano actúa en la historia, se reserva el juicio acerca de lo que hace avanzar o no a esa meta: la historia universal es el tribunal universal desde el que se pronuncia el iudicium maximum. Tras todas estas reflexiones, Koselleck afirma que «en cierta medida está parcialmente justificado hablar en sentido auténtico de mundanización de las metas cristianas» ${ }^{16}$. Una vez más, se atiene a Carl Schmitt y muestra sus reservas por Blumenberg. Hay una transposición de una meta extrahistórica a una intrahistórica, dice en una nota ${ }^{17}$. Nada por

9 «El tiempo moderno difiere de la teoría anterior de las edades en que no se experimenta ex post, sino inmediatamente» (Idem, p. 323). La inevitable consecuencia es la definición de progreso

10 «La utopía de futuro de Mercier es una variante de la filosofía del progreso, y su fundamento teórico es la temporalización de la perfección ideal». En cierto modo, tal cosa tiene aspectos antiapocalípticos. Cf. el trabajo «Die Verzeitlichung der Utopie», en R. Koselleck, Zeitschichten, op. cit., pp. 131-150.

11 Koselleck, Aceleración, prognosis y secularización, op. cit., p. 62.

12 Idem, p. 48.

13 Idem, p. 54.

14 En frase de Wieland, Idem, nota 29 a la p. 59.

15 Koselleck, op. cit. p. 54.

16 Idem, p. 55.

17 Idem, p. 60. 
tanto de autoafirmación moderna, una tesis que a pesar de todo requiere ser matizada.

Koselleck ha reconocido que de ahí se deriva el tiempo entendido como progreso ${ }^{18}$. Lo histórico y lo progresivo, son dos caras de la misma Jano. Además, para él progreso es igual a aceleración y la implica ${ }^{19}$. Aquí identificamos al hombre contemporáneo, que por la aceleración ha roto los equilibrios de acción y reflexión, de experiencia y expectativa, de diagnóstico y pronóstico, y donde la historia magistra vitae desaparece como clave de todas las estructuras de compensación. Aquí entramos en el mundo en el que la política ha sido desplazada de su centralidad y del que Luhman dijo: «con ello está asegurado que la empresa política no se mantiene en una simple continuidad con la política tal y como se entendía hasta ahora. En lugar de esto, y ésta es la función de la elección política que se ha de repetir regularmente, la política se confronta con un futuro para sí desconocido» ${ }^{20}$.

\section{Distinciones conceptuales}

En este paso, creo que Koselleck se precipita. En realidad, que las promesas del reino de Dios se deban realizar en el tiempo, no implica aceleración. Temporalización inmanente, historificación radical ${ }^{21}$, no implican ni aceleración ni progreso en general. Aunque Koselleck parece sugerir que la conciencia de la aceleración es necesaria para una «experiencia del tiempo específicamente histórica», una cosa no parece seguirse de la otra ${ }^{22}$. Hegel no sabe nada de aceleración ni de progreso en el sentido del infinito malo y conoce perfectamente la traducción del reino de Dios y sus promesas en el tiempo histórico. El espíritu del mundo de Hegel sólo da rodeos y no acorta su experiencia, ni tiene prisas ni se aburre ${ }^{23}$. Ni progresa ni retrocede: acumula mediaciones

18 «El nuevo tiempo fue idéntico con el progreso». Idem, p. 323. Sería la primera determinación del tiempo secularizado, al margen de la teología o del mito. Se trataría de una reflexión genuina sobre el tiempo histórico. Supone como tal el tiempo de la planificación y de la reflexión.

19 De hecho, las dos palabras pasaban a ser empleadas ya sin solución de continuidad en este ensayo (idem, p. 325).

20 N. Luhmann, Die Politik der Gesellschaft, Frankfurt, Suhrkamp, 2000, p. 104. En esta misma medida, todo el contenido del segundo ensayo del volumen está cantado: «Los pronósticos sólo son posibles porque hay estructuras formales que se repiten». Esa repetibilidad estructural ahora sería contraria a sí misma porque sería meramente aceleración del tiempo de la novedad.

21 Esta nueva experiencia del tiempo, una nueva forma de comprensión de la historia, impone una exigencia a la filosofía: «todas las tareas y desafíos deben ser resueltos en el tiempo histórico, con y a través del tiempo histórico mismo».

22 Koselleck, op. cit., p. 47.

23 El propio Koselleck lo sabe: «Aber der Weltgeist [...] der nur auf Umwegen und über Vermittlungen fortschreitet: 'Er hat nicht nur Zeit genug', es kommt ihm auf Zeit gar nicht an. Und 'was die Langsamkeit des Weltgeistes betrifft, so ist zu bedenken: er hat nicht zu eilen; er 
conceptuales en las que sólo algo queda permanentemente desdeñado: el tiempo. Otro ejemplo: Por mucho que Kant haya apostado por el progreso jurídico, y por la realización de todas las metas humanas en el tiempo, no ha defendido una teoría de la aceleración en el ámbito moral. El propio Lessing, citado por Koselleck, puso reparos a la hora de confundir ambas cosas. En suma: temporalización de la utopía, historificación, no es per se progreso ni aceleración. Tampoco lo implicaron las propuestas de institucionalización mundana del cristianismo. No todas las instituciones se basan en el tiempo acelerado, como saben Plessner y Gehlen. Como símbolo mundano de la Ciudad de Dios, la Iglesia institucional es un modelo que atraviesa todo el tiempo, temporaliza la utopía, pero ni conoce el progreso ni acelera el tiempo.

Doy razones para sugerir que Koselleck identifica demasiado rápidamente mundanización, temporalización y aceleración ${ }^{24}$. Cuando se miran desde el largo plazo histórico, sus propuestas me parecen precipitadas. Si nos preguntamos si la mundanización puede explicarse al margen de su modelo y origen cristiano, al asumir la herencia del mundo romano, debemos decir que no. Es el propio cristianismo, en su síntesis evolutiva cada vez más intensa, culminada en 1075 con la revolución de Gregorio VII ${ }^{25}$, el que institucionaliza y mundaniza la Ciudad de la Tierra a imagen y semejanza de la Ciudad de Dios. Si nos preguntamos si hay que explicar la temporalización — valoración del tiempo histórico como lugar en el que se realizan las promesas o los fines - «a partir de su origen cristiano», y si es una consecuencia de la mundanización, creo que podemos responder que en modo alguno. Durante mucho tiempo el cristianismo estuvo institucionalizado - Iglesia como institución permanente - y mundanizado - Iglesia expansiva en el mundo- $\mathrm{y}$, sin embargo, no se asumieron las tesis de que las promesas de la salvación se pudieran realizar en el tiempo. Ambos aspectos se mantuvieron como preparatorios dentro de un horizonte apocalíptico que clausuraba la historia desde «afuera» del tiempo, afuera desde el cual Dios podría cumplir sus promesas. Durante todo este período histórico largo-medieval, la experiencia del tiempo fue histórica y mundana, y se quiso traducir la utopía a inmanencia, pero no fue una experiencia del tiempo plenamente inmanente. En realidad, sólo se podía interpretar como el juego de inmanencia y trascendencia, de acciones de los hombres y decisiones de Dios.

$\mathrm{Y}$ es aquí donde creo que Koselleck no identifica lo esencial. Los seres humanos quisieron asegurar la relación con la utopía trascendente, primero

hat Zeit genug — tausend Jahre sind vor dir wie ein Tag-; er hat Zeit genug, eben weil er selber ausser der Zeit, weil er ewig ist». Se cita aquí Einleitung in die Geschichte der Philosophie, hrg. J. Hoffmeister, Hamburg, 3. ${ }^{\text {a }}$ ed. 1959, pp. 62 y 64.

${ }^{24}$ Koselleck, op.cit., pp. 46-47. Aquí dice que sería más correcto llamar temporalización a la mundanización. Sólo por la temporalización se puede hacer de la aceleración el tiempo propio de la historia.

25 Harold Berman, La formación de la tradición jurídica de Occidente; México, FCE, 1996. 
mediante el dominio del espacio — sea el bidimensional de las figuras pintadas, o el tridimensional de las catedrales en el Románico-, luego mediante el dominio del tiempo y la voz — canto gregoriano de Cluny y Císter-, después mediante la estructura conceptual racional de la potestas y la jurisdictio papal y luego mediante la realización de determinadas condiciones necesarias para que Dios se decidiera a irrumpir por segunda vez en la historia. Este camino - que las decisiones de Dios estaban condicionadas por acciones de los seres humanos - es el que otorga cada vez más relevancia a la acción en el tiempo y el que conduce a la temporalización. Antes de que la historia llegara a tener valor absoluto, fue relevante como condición racional de la decisión de Dios. Lo determinante es que sólo en algunas formas de entender estas condiciones humanas de la decisión de Dios emerge como relevante el problema de la aceleración. Si nos preguntamos por tanto si es necesario que la aceleración se derive de la secularización, último paso de la mundanización y de la temporalización, creo que volveríamos a decir que en modo alguno. Como voy a defender, hay aceleración en el ámbito medieval, aunque en él sólo hay una temporalización inicial, y no hay secularización en sentido propio, pues se sigue concediendo legitimidad soberana expresa a la instancia cristiana. El análisis de Koselleck es simplificador y no describe bien la experiencia histórica occidental.

En suma, decir que el acortamiento propio del Apocalipsis cristiano se debe presentar como aceleración profana, última consecuencia de la secularización, proceso que ultima la mundanización y la temporalización, constituye un relato ingenuo, aunque seductor. Como veremos, la clave reside en que Koselleck ha privilegiado las relaciones intuitivas entre acortamiento y aceleración. Como siempre, lo racional debemos buscarlo más bien en lo anti-intuitivo. En realidad, creo que Koselleck trabaja con un esquema evolutivo simple. En una metodología de historia de los conceptos, que quiere marcar las discontinuidades, no es un problema menor.

\section{Razones para defender la teoría de la secularización}

Tenemos así que desde el punto de vista del largo plazo, hay muchos pasos dudosos en el planteamiento de Koselleck. Y sin embargo, su apego a la teoría de la secularización es muy profundo. Si tuviera que explicarlo, creo que diría lo siguiente: en el fondo, el gesto de Koselleck tiene un gusto muy conservador. Él quiere decirnos algo así: La ilegitimidad de la secularización trae malas consecuencias; por ejemplo, la inevitable aceleración del tiempo. Al simplificar los puentes históricos que se deben edificar entre la institucionalización, mundanización, temporalización y aceleración, al proponer un tránsito demasiado inmediato entre ellos, Koselleck, como Schmitt, deseaba mostrar la carencia de autonomía del mundo moderno, cuyo colapso espiritual se 
presiente en la aceleración como forma de la experiencia del tiempo. A su manera, deseaba insistir en la transferencia ilegítima de categorías que sólo tienen sentido propio cuando juegan en el contexto de la trascendencia. El acortamiento del tiempo lo decreta Dios. La aceleración es una imitación del hombre, nos dice ${ }^{26}$. Pero entre la institucionalización, la mundanización, la temporalización y la aceleración no se da algo así como un proceso histórico unitario, un gran relato que pueda ser entendido con el nombre de secularización y que ahora por fin muestra sus consecuencias nefastas. Así que la huella de esta transferencia quiere sugerirnos un aspecto apocalíptico de la propia secularización y emancipación. «Por de pronto, conviene no excluir que las antiguas visiones apocalípticas de decadencia sean superadas con creces en el terreno empírico por la capacidad humana de autoaniquilación» ${ }^{27}$. Aquí la teoría de la secularización y de la emancipación se pone al servicio de una reivindicación genuina del cristianismo: las usurpaciones y las infidelidades se pagan con el Apocalipsis de la amenaza nuclear. La soberbia del hombre prepara su castigo. La teoría de la secularización del Apocalipsis es un fragmento de la mentalidad apocalíptica ${ }^{28}$. En cierto modo, ésa es su profunda verdad.

Y sin embargo, al reconocer que «las esperanzas cristianas continúan siendo un presupuesto implícito para pensar la mundanizacion» ${ }^{29}$, Koselleck parece extraer la consecuencia de que todos estos aspectos nefastos se corregirían desde una apropiada comprensión de las promesas cristianas, desde una cierta resistencia a la secularización, desde un cierto nietzscheanismo. El último gesto de Koselleck es igualmente el de Schmitt. Como tal, es el repliegue definitivo de la secularización y de la teología política. «En términos políticos, lo importante es saber quien acelera o retarda o quién o qué, dónde y cuándo» ${ }^{30}$. Esto es: lo importante es quien asume la función de katechontos. $\mathrm{Y}$ éste sería un soberano compensatorio del soberano que acelera. Aquí se concitan todos los anhelos de la revolución conservadora, de la compensación de las ciencias del espíritu respecto a las ciencias de la naturaleza, etcétera. Creo que ésta es la clave de su posición.

26 «La experiencia de la aceleración, en virtud de la cual se califica el tiempo histórico de tiempo producido específicamente por los hombres». Koselleck, op. cit., p. 46.

27 Idem, p. 68.

28 Sin embargo, al parecer de Koselleck todavía habría tiempo. Tal vez estemos en una fase de transición. Quizá haya tiempo de recolocar las cargas de aceleración y detención, de novedad y supervivencia (cfr. Idem, p. 71).

${ }^{29}$ Idem, p. 48.

30 Idem, p. 71. 


\section{Otra descripción: tiempos históricos fundamentales y experiencias del tiempo}

Koselleck no se ha visto obligado a corregir este gran relato porque al escribirlo ha operado como filósofo, no como historiador de los conceptos políticos. Era consciente de que su tesis, «considerada empíricamente, admite, como es natural, muchísimas formas intermedias» ${ }^{31}$. Pero no se trata de consideración empírica, sino de historia de los conceptos guiada por las claves de la histórica. Como es sabido, el centro mismo de la historia de los conceptos pretende descubrir las experiencias temporales fundamentales, ésas que juegan como una estructura trascendental y determinan la experiencia histórica en el largo plazo. Ellas enmarcan el sentido de los esquemas de la histórica y de los conceptos políticos como índices y factores. Es curioso que la carcasa del Apocalipsis determine la experiencia básica del tiempo, pero también el sentido de todos los esquemas de la histórica — dentro-fuera, amigo-enemigo, padres-hijos, público-secreto, mando-obediencia ${ }^{32}$ - . Además, muestra la necesidad de proponer un nuevo par de esquemas para la histórica, un par que puede registrarse de muchas maneras, como inmanencia o trascendencia, finitud e infinitud, o por decirlo con Blumenberg, tiempo de la vida y tiempo del cosmos.

Es curioso que Koselleck, que ha señalado de manera clara que «la cuestión de las estructuras temporales es una conditio sine qua non del conocimiento socio-histórico», no haya reparado en esta condición estructural del Apocalipsis ${ }^{33}$. Si la característica de las estructuras de largo término es la repetición, ninguna se repite tanto como el Apocalipsis, y no sólo en la Edad media, cuya invención tan decisiva fue para la noción de historia moderna ${ }^{34}$. Esto lo sabe Koselleck, pero no lo tematiza ${ }^{35}$. Quizá la razón de este descuido sea la valoración, incluida de pasada por Koselleck, de que «La interpretación apocalíptica, apenas fue aplicada a acontecimientos políticos e históricos concretos, cayó muy pronto en el ámbito de la herejía». Incluso dice que «en las postrimerías de la Edad Media proliferaron y ganaron autonomía las visiones apocalípticas que se sustrajeron al control de la Iglesia católica» ${ }^{36}$. Así se pondría en movimiento la crítica revolucionaria, que llevaría por línea directa

31 Idem, p. 48.

32 Cf. para todo esto mi trabajo «Histórica, historia social e historia de los conceptos políticos», en Res Publica, 11-12, Año 6, 2003, pp. 69-95.

33 «Moderne Sozialgeschichte und historische Zeiten», en Zeitschichten, op. cit., p. 327.

34 Idem, p. 328. Sin embargo, Koselleck se entregó en este ensayo a definir una dialéctica entre estructura temporal y acontecimiento que conducía a una aporía. Cf. 329. Luego, el tercer capítulo pretendía definir las relaciones entre espacio de experiencia y horizonte de expectativa, como forma de juntar el pasado y el futuro de una manera siempre asimétrica.

35 «Es una constante de las predicciones apocalípticas el hecho de que puedan ser continuamente repetidas» (Aceleración, prognosis y secularización, op. cit., p. 51).

36 Idem, p. 50. 
a Robespierre y a Lenin. Pero la dialéctica entre Apocalipsis, institucionalización, temporalización, historificación y aceleración no puede entenderse desde el ámbito de la herejía, de la crítica, ni de los que anhelan ardientemente el día del Juicio como Lutero. La profecía y la conciencia apocalíptica medieval en modo alguno se describen bien cuando se hacen depender sólo de Joaquín de Fiore y su sorprendente corrección del viejo esquema de las Seis Edades con el esquema de las Tres Iglesias.

La tesis que vincula herejía y Apocalipsis supone una afirmación histórica que en sí misma parece indudable. Ahí está el libro de Norman Cohn para afirmarlo. Sin embargo, este texto sólo presta atención a uno de los usos del Apocalipsis. Sin duda a él se refiere Koselleck cuando afirma: «los pasajes relativos al acortamiento del tiempo se convierten casi bajo mano en argumentos históricos sobre la aceleración». Éste es el único soporte probatorio de su tesis de que «el presupuesto extrahistórico del acortamiento del tiempo se troca al principio de la Edad moderna en un axioma intrahistórico de aceleración» ${ }^{37}$. La emancipación intramundana y crítica se conecta así a los ritmos temporales apocalípticos. La acción moral, acósmica, revolucionaria, impulsada por los seres humanos, aumentando la diferencia entre el caos, la confusión y la bondad de las comunidades de fieles, no era la realización del Juicio, sino la condición para que Dios acelere su venida. Este esquema es el de la irrupción revolucionaria. En realidad, todo está diseñado para mostrar cómo la religión espuria de los movimientos cristianos heréticos, inspiró los movimientos revolucionarios, desde la Revolución francesa a la comunista, en la línea del pensamiento de Ernst Bloch. Sin embargo, con estos esquemas no agotamos los usos históricos del Apocalipsis, ni entendemos el problema de la aceleración en el sentido que nos llega al presente en línea directa desde Comte.

Cuando recogemos los textos que aporta Koselleck sobre aceleración descubrimos en ellos dos dimensiones bien distintas. Una procede del ámbito de la moral y de la justicia - los seres humanos deben convertirse y destruir los órdenes de poder mundanos como condición de que Dios se acuerde de ellos-; la otra procede del ámbito de la ciencia y de la técnica. Ésta es la conclusión que se deriva de un artículo muy anterior al que estudiamos, titulado precisamente Gibt es eine Beschleunigung der Geschichte?, que es una conferencia de $1976^{38}$. En realidad fue su primer intento de examinar los presupuestos apocalípticos del axioma moderno de la aceleración. Aquí, como en otros sitios, Koselleck habló de la desnaturalización de la experiencia del tiempo a partir de los factores de la aceleración científico-técnica. El punto de partida es Bacon, con su «longe plura et meliora atque per minora intervalia»» ${ }^{39} \mathrm{y}$ pasa por cierto a Kant, el positivismo y la in-

37 Idem, p. 62.

38 Ahora editado en Zeitschichten, op. cit., pp. 150-176.

39 Bacon, citado por Novum Organum, Buenos Aires, Losada, 1961, p. 148. Cf. Koselleck, op. cit., p. 53. 
dustrialización y llega hasta hoy. Pero este pensamiento se aplicó también a la esfera de lo político-moral y trató de democratizar y hacer justicia en la tierra. Ambos aspectos tienen que ver con «dominar la naturaleza y organizar de forma justa la sociedad» ${ }^{40}$. La caracterización ejemplar es la de A. Comte. Ambos telos imponen una «réorganisation total qui peut seule terminer la grande crise moderne» ${ }^{41}$.

Sin embargo, en aquella conferencia de 1976, y refiriéndose a este doble telos como meta del tiempo, dice Koselleck: «Se trata aquí de algo más y de otra cosa que de una mera secularización. Por mucho que las expectativas apocalípticas bajo el ropaje de esperanzas milenaristas puedan estar inmersas en el nuevo concepto de aceleración, el núcleo de experiencias que invocan las nuevas expectativas no era derivable del Apocalipsis». Así que aquí parece sugerirnos Koselleck que hay una forma del tiempo histórico - aceleración- derivada de la forma del tiempo del Apocalipsis, mientras que hay una expectativa material - dominio y orden de la tierra - que no es derivable del Apocalipsis ni es mera secularización. Por lo que sigue del texto, se supone que esto no derivable es la dimensión de tarea del ser humano, la comprensión de la historia como «modo de ser propio del ser humano». Por eso pudo hablar de «analogía formal» ${ }^{42}$ y de la «formale Zeitstruktur ${ }^{43}$ » de la aceleración con el acortamiento, «pero no más». Luego insistió en lo nuevo de la meta intratemporal frente a la meta extratemporal del Apocalipsis. A esto le llamó Umsetzung der apokalyptischen Tradition.

Esta referencia al trabajo de 1976 me parece relevante porque muestra los supuestos de Koselleck y nos informa acerca de su sentido primario. No puede haber vigencia de la tradición apocalíptica cuando el actor principal pasa desde Dios al ser humano. Esto es algo más que una transferencia de sentido de estructuras formales o una secularización. Esto implica una transformación, una permutación. La tradición apocalíptica puede ser crítica y anarquizante y por eso confía en la trascendencia de Dios y en la violencia divina. Por eso sólo puede trasladar una forma temporal, el acortamiento, no un protagonismo al ser humano. Por eso no puede ser usada como matriz para explicar el programa de dominio y de reorganización total de la crisis. Este punto se concentra sobre lo ilegítimo de un programa de salvación que quiere mantener sus promesas vigentes desde la mera acción del ser humano.

Esta posición no puede mantenerse desde el punto de vista histórico. Cuando nos referimos a ella, descubrimos que la acción humana fue cada vez más

40 Gibt es eine Beschleunigung der Geschichte?, op. cit., p. 171. También Aceleración, prognosis y secularización, op. cit., p. 59 para Robespierre, que ya habla de «aceleración» como deber moral.

41 Auguste Comte, Cours de philosophie positive, ed. de Ch. Le Verrier, 2 vol., París, 1949, II, pp. 114 y 157 ss. Citado en R. Koselleck, Zeitschichten, op. cit., p. 174, nota 33.

42 Idem, p. 172.

43 Gibt es eine Beschleunigung der Geschichte?, en: Idem, p. 174. 
determinante y condicionante, más significativa e inductora de la acción de Dios. El proceso de racionalización también se dio en estos ámbitos. También en estos escenarios quiso el ser humano asegurar que su acción era apropiada respecto a la decisión de Dios de poner punto final al mundo. La racionalización entonces también sirvió al aumento del poder. La experiencia apocalíptica desde siempre sirvió no sólo a la política por medio de la herejía, sino a la construcción de poderes y al programa de dominio tanto de la naturaleza como de la sociedad. De hecho, la apelación a la experiencia del Apocalipsis siempre jugó en el seno de la aspiración a configurar poderes totales y legítimos, capaces de preparar la tierra a la segunda llegada de Cristo. Fue desplegada como forma de imponer obediencia desde las instancias legítimas de la sociedad —el Papado o el Imperio - en momentos identificados como de crisis total. Su aspiración a reorganizar la totalidad de la sociedad estaba relacionada con su exigencia de dominio de los recursos materiales a su disposición, dada la razón absoluta de ser la configuración final de la sociedad humana.

En este sentido, la experiencia del acortamiento del tiempo estuvo pronto mediada por la formación de poderes capaces de lograrlo. Fue un aumento ingente de poder en un soberano entendido como legítimo el que permitió acariciar la idea de que el acortamiento del tiempo prometido por Dios a los suyos se cumpliría. La fe en el acortamiento se racionalizó con las evidencias de la aceleración. Estas evidencias confirmaron la fe de la pronta acción de la trascendencia y le dieron su certeza. Tal aceleración fue obra de los poderes legítimos de la Iglesia y de los candidatos al Imperio, y dejó a la omnipotencia de Dios el acortamiento. La forma en que esa aceleración se manifestó no podía ser otra que la de acumulación de poder mundano, pues la tierra se preparaba para la irrupción de la Omnipotencia divina desde un vicario mundano omnipotente. Por eso, la llamada Umsetzung del agente Dios al agente ser humano no es tan nueva ni tan ajena a la estructura de la tradición apocalíptica. Al contrario, tan pronto como determinados poderes fueron vistos como sagrados, se puso en su mediación la tarea de acumular de forma acelerada su poder para que Dios acortara el final. El hecho de que estos poderes se vieran inmersos en una crisis siempre creciente de mal, determinó que este acortamiento del tiempo del final llevara consigo la forma de una batalla final y este hecho implicó que se reclamaran dos cosas: un aumento ingente de dominio y un control general de la naturaleza y de los hombres (que se pretendiera primero por medio de la magia y luego de la ciencia no es una gran diferencia). Este aumento acelerado de poder, si había de acortar el tiempo del final, sólo se podía percibir en una clara victoria final, en la recomposición de la tierra, en la configuración del éxito. La manera de asegurar el acortamiento del tiempo fue aumentar el poder sobre toda la Tierra, y la manera de percibirlo fue la aceleración control, su demostración de ocupar la tierra, su triunfo y su reorganización total. Pero esta demostración no redundó en la transferencia de acción de Dios al ser humano, sino que siempre implicó una dialéctica de 
tiempo del hombre y tiempo de Dios, una relevancia de la acción del ser humano respecto a la decisión soberana de Dios, la estructura básica de toda la ingente racionalización occidental. Mas esto sólo se podía llevar a cabo mediante la presentación de ciertos seres humanos como dotados del especial carisma de la omnipotencia, como las herramientas de Dios en la tierra, las que habían de hacer el necesario trabajo preparatorio de su regreso. Así se creó un hueco en la tierra para un ideal de omnipotencia, que se ha repetido como matriz siempre a lo largo de la modernidad y que ha invocado estructuras apocalípticas. No sólo la revolución anarquista se ha beneficiado de este esquema, sino todos los poderes totalitarios.

Los efectos del final apocalíptico han tenido dimensiones constituyentes sobre los poderes mundanos. Mas también sobre los contrapoderes revolucionarios. La constitución de estos poderes totales siempre estuvo sometida a la ambigüedad de una valoración como meros poderes profanos, que no eran vicarios de Cristo, sino del Anticristo. Unos y otros aspiraron a la omnipotencia y ésta se mostró en la aceleración de los efectos de su poder. La manera de controlar el acortamiento del final, ya fueran representantes de Dios o del Demonio, fue la aceleración. En uno y otro caso, estos poderes asumieron de manera clara una relación con la esperanza apocalíptica: se vieron como los fundadores de una nueva Edad de oro, como una nueva tierra en paz y en esplendor de la unidad del mundo. Esto es lo que sucedió en las propuestas de Alfonso X, y tras las luchas del Cisma, lo que acaeció en la recomposición posterior de la idea de la colaboración del Papado y del Imperio que sostiene la acción política de Fernando el Católico. El primer episodio lo he analizado en mi estudio sobre Alfonso X en La formación de los reinos hispánicos. Para entender el segundo basta repasar el libro profético de Alonso de Jaén, Espejo del mundo, sobre el papel de Fernando el Católico. Sólo así se podrá comprender el sentido de la monarquía que se pone en marcha en esta época. Mas éste fue también el uso del pensamiento profético en la época de Carlos I, y sus derivados Austrias, y hasta ahí llega la Edad Media. Tras ella, la mal llamada época del Estado, en realidad la época del aumento continuo de la potencia estatal, no hizo sino aplazar y desplazar esta confirmación racional de la construcción de la omnipotencia mediante la teoría del progreso. El Apocalipsis de esta forma se había hecho continuo y disciplinado, su cápsula temporal racionalizada.

\section{Nota fenomenológica sobre el tiempo presente}

Así que podemos comenzar disolviendo la secuencia entre acortamiento y aceleración. Convivieron durante siglos: ésta era la acción del ser humano, la otra la acción de Dios. De su dialéctica brota la historia política tal y como podemos entenderla en el largo plazo y su condición global, que por eso tuvo 
su primera manifestación en el imperio católico hispano. Por eso esta dialéctica entre tiempo del hombre y tiempo de Dios tiene efectos constituyentes desde siempre y no desde la modernidad. Racionaliza la relación entre la acción del ser humano y la acción de la trascendencia y nos muestra que la teoría de la racionalización es un continuo histórico. Ya Weber habría intuido esto, más allá de su Ética protestante. Es muy curioso que ya Weber viera que la historia de la racionalización de la música forma parte central de esta historia de la racionalización, porque forma parte central de esta dialéctica entre acción de los hombres y acción de Dios.

Y sin embargo, esa dialéctica no es siempre la misma, desde luego. Lo propio de la actualidad constituye su aparente quiebra. De jugar de forma proporcional aceleración y acortamiento, hemos pasado a una contraposición puramente fenomenológica y empleo esta palabra con plena propiedad filosófica, lo que aquí sólo puede significar un recuerdo a don Fernando Montero. Durante mucho tiempo la aceleración de acumulación de poderes confirmó que Dios acortaba el final. Hoy, aparentemente, la aceleración no tiene relación alguna con el final. La aceleración propia del tiempo pleno de la inmanencia, en sí mismo indefinido, parece ser el único medio para dotar de sentido una realidad, el tiempo, que de otra manera sería el escenario del andar perdido. El resultado de la aceleración es, desde luego, el acortamiento de todo lo que vive en el tiempo, pero no el acercamiento de la meta. Hay algo así como una hostilidad sádica contra todo lo que se nos da en el tiempo cuando éste se desea acelerar. Y hay algo así como una confesión de su insoportable vacío cuando se evade la experiencia de la serenidad como contemplación del tiempo puro. Y sin embargo, no por ello deja de operar una dialéctica entre tiempo del ser humano y tiempo de la trascendencia, por mucho que ésta sea una dialéctica negativa. Y es que, repito mi impresión, esta dialéctica forma parte de la histórica y es una condición de la pluralidad de las historias. Y desde luego, de su escritura.

Y sin embargo, esa dialéctica negativa puede tener un sentido más bien positivo. Ya no creemos que el tiempo acelerado de la inmanencia se acorte un ápice por su aceleración, ni pensamos que llegue al final por ella. Aquí estamos hablando de aceleración de la experiencia, de la frecuencia en la presencia de contenidos nuevos, tan irrelevantes como los anteriores y más perecederos todavía. No se acorta el tiempo, sino la experiencia y la medida del tiempo a través de la novedad y de su creciente sustitución por otros contenidos nuevos. Tenemos la situación existencial del hombre europeo: no puede dejar de pensarse como si hubiese de llegar a algún sitio. Esa sería la aceleración: comportarse como si se llegara a algún sitio. En realidad, se explora así la posibilidad de transformación y metamorfosis de la tierra, la flexibilidad de una materia finita para convertirse en infinita, en el objeto anhelado de nuestro deseo. Hoy tenemos la sospecha de que el ser humano se entrega a esta experiencia porque no puede soportar el tiempo desde el interior del tiempo 
mismo, como ya Kant sabía que no se puede ordenar la sucesión pura desde el propio sentido interno. La aceleración actual sería así la liberación de una pulsión de muerte general que desea explorar el sentido del tiempo desde la previsión de la catástrofe. Ésta es la decisión trascendente que se quiere acortar. Llegar a algún sitio es una experiencia trascendente respecto al tiempo. Hoy la acción humana quiere condicionar la voz dolorida de la tierra en su colapso final. Todo antes de la desesperación de estar y de sentirse solo.

Pero en esta relación entre la inmanencia de una aceleración y la esperanza de una decisión de la transcendencia, el principio de realidad, el ser humano continúa una vez más con lo fundamental: intenta asegurar racionalmente la decisión apocalíptica. 